\title{
Comments on 'New contexts, new challenges: revisiting equal opportunities, particularism, and ethnic relations' by Malcolm Harrison
}

\section{'Are you local?': a reply to Malcolm Harrison on the dilemmas of localist particularism}

\author{
Paul Watt* \\ Department of Geography, Environment and Development Studies, Birkbeck, \\ University of London
}

\section{Introduction}

In his thought-provoking paper 'New contexts, new challenges: revisiting equal opportunities, particularism and ethnic relations', Malcolm Harrison has sketched out how one can move beyond certain aspects of what one can term the "equal opportunities' agenda in the quest for a more socially just notion of welfare. I found much to agree with in the paper. As someone who has spent a considerable part of their career teaching and writing about social class, I appreciate Harrison's insistence on the importance of class inequality which remains a stubbornly tenacious feature of the British social landscape. In addition, his comments on the lack of voice and stigmatisation of social housing tenants are extremely welcome (see also Johnston and Mooney, 2007; Watt, 2008). In the rest of this reply, however, I want to focus upon the later section of Harrison's paper regarding the significance of localism as a potential basis for particularism.

\section{Neighbourhood contestation and the 'local'}

A localist form of particularism means 'the idea that local people should collectively have some acquired rights over neighbourhoods, resources and services where they or their communities traditionally live' (Harrison, 2009: 20). This idea has parallels with the 'right to the city' notion in critical urban studies. From the latter perspective, DeFilippis (2007) argues that one way of moving beyond what he calls 'neoliberal communitarianism' (p. 275) and the dominant current policy emphasis on social 
p. 148. Comments on 'New contexts, new challenges: revisiting equal opportunities, particularism, and ethnic relations' by Malcolm Harrison

capital 'deficits' in deprived areas, is to embrace alternative forms of property development which better link people to the physical space of their community as well as to each other. Positive examples in the U.S. context that DeFilippis singles out include limited equity housing co-operatives and community land trust models, and Harrison also mentions co-operatives in his paper.

I have considerable sympathy with this kind of argument, not least since, as Harrison argues, such policies could help to provide some form of "consumer insulation' for vulnerable groups against the increasingly dramatic and damaging vagaries of the market. However in the spirit of critical although not unsympathetic dialogue, I want to highlight several concerns I have regarding localist particularism. Harrison does not actually make clear what spatial scale his localism refers to although it seems to be the 'neighbourhood', itself a slippery concept as I discuss below. In my own research across several urban, suburban and rural areas in London and South East England, I have certainly found evidence of shared 'local' interests and identities, for example around day-to-day neighbouring activities (Watt, 2006) and in a campaign to oppose a housing stock transfer (Watt, 2008). Established BME groups can share in this localism on the basis of residential longevity coupled with respectability (Watt, 2006), and/or via common political projects (Watt, 2008). At the same time, I have been repeatedly struck by the socially and spatially contested nature of the local, including in relation to neighbourhoods. Indeed, as I argue in a forthcoming paper, what is local can itself be a constituent element in Bourdieusian processes of sociospatial distinction as affluent suburban homeowners distantiate themselves from lower-class 'local' people and places in the neighbourhood (Watt, 2009a).

Furthermore in relation to urban policy, severe doubts exist as to the efficacy of New Labour's valorisation of the neighbourhood as both a space and conduit of regeneration and active citizenship and whether it amounts to anything more than a communitarian brand of neo-liberalism (DeFilippis, 2007; Fuller and Geddes, 2008; Watt, 2009b). Part of the problem lies with the 'neighbourhood' itself which, as Whitehead (2004: 68) convincingly argues, has been over-laden with policy expectations since, "neighbourhoods do not exist as neatly segregated physical [...] or social spaces [...] within the city. Neighbourhoods are contested fragments of city space, the formation of which can be as divisive as it is harmonising and as exclusionary as it is inclusive'. Much, although by no means all, of this contestation takes the form of multi-layered social conflicts over resource distribution. This can be seen in inner-city areas and outer-estates where the various shards of the 'local' working classes blame those 'others' who are perceived, for whatever reason (residential longevity, migrant status, ethnicity, roughness, etc.), to make illegitimate claims on resources and especially on public welfare resources (Watt, 2006; Garner, 2009).

In the realm of housing, this contestation and blaming is underpinned by widespread worsening shortages of council and registered social landlord (RSL) rental provision as well as by outstanding housing needs issues such as overcrowding (Garner, 2009; Watt, 2009c). To illustrate this point, I will briefly refer to archival research I conducted as part of a project examining the Ocean Estate New Deal for Communities in Tower Hamlets (Watt, 2009b). This included consulting all the housingrelated articles and letters in a local newspaper, the East London Advertiser, over the 2004-06 period. What this analysis revealed is the appalling human cost of the social housing shortages and sub-standard housing conditions that many low-income BME and white Tower Hamlets residents are faced with ('Tenants' fury over fungus: pensioners welcome New Year in damp flats that make them seriously ill', East London Advertiser, 2 January 2004; 7 to a flat crisis: 12,300 overcrowded homes in East End prompts help plea', East London Advertiser, 3 August 2006). The newspaper printed 
p. 149. Comments on 'New contexts, new challenges: revisiting equal opportunities, particularism, and ethnic relations' by Malcolm Harrison

letters from frustrated and even desperate residents who have been left languishing on council housing waiting lists for years ('Why I want to kill myself', East London Advertiser, 15 January 2004). As one might expect, some of these letters took a racialised format as white East Enders either compared themselves unfavourably with migrant/ethnic 'others' ('Knowing when you're well off', East London Advertiser 9 June 2005), or blamed the latter for the lamentable housing conditions that they and their family/friends/neighbours were living in ('Housing: our kids are told "no chance"', East London Advertiser, 25 November 2004).

As Garner (2009) discusses, this is the sort of localised resource contestation that the far right British National Party (BNP) attempts to capitalise upon amongst the disgruntled 'white working class', with an unfortunate albeit unsurprising degree of success in certain parts of the country. One also needs to highlight, however, that the current social housing deficit is very largely a matter of housing policy failures including New Labour's over-reliance upon the RSL sector to deliver new affordable rental properties (Watt, 2009c). As Jon Cruddas (2006), Labour MP for Dagenham, has argued in relation to the election of 11 BNP councillors in the London Borough of Barking and Dagenham in 2006, "the fundamental policy failure that has underpinned this extremism lies in the lack of provision of low cost social housing in a borough built upon the principle of socialised council housing' (p. 18). In relation to this, I am somewhat surprised that Harrison tends to skirt over the materialist nature of inadequate social housing provision, a phenomenon which is certainly acute in London but is by no means confined to the capital as testified by spiralling local authority waiting lists across the country (Watt, 2009c, Table 12.4).

If the local can often be a site of social contestation, it can also be a site of spatial contestation as seen for example in relation to urban regeneration programmes. In his research on the formation of Local Neighbourhood Committees (LNCs) in Walsall, Whitehead (2004) illustrates two geographically divisive aspects of implementing neighbourhood-based democracy vis-à-vis regeneration. Firstly are the disputes between those areas with LNCs and adjoining areas without such representation or funding. This is the well-known boundary problem which can exist in housing renewal and regeneration schemes whereby residents in non-targeted neighbourhoods are annoyed at missing out on what state largesse is being bestowed upon their nearby recipient neighbours, i.e. 'why there and not here'? Secondly, because of differential funding allocation between the various LNCs, "a series of "neighbourhood feuds" have emerged in Walsall' (Whitehead, 2004: 69) based upon inter-neighbourhood funding disparities. Therefore efforts to implement neighbourhood democracy in Walsall appear to have fostered conflict and fragmentation rather than consensus and community.

\section{Conclusion}

Whilst I empathise with Malcolm Harrison's rationale for localist particularism, I also have considerable doubts over how far the 'local' (the neighbourhood), can bear the weight of emphasis that he places upon it. Such doubts include the crucial issue of resources. An adequate supply of quality social rental housing, for example, requires large-scale public investment which New Labour at central government level has been notably reluctant to contemplate during its tenure. New Labour's belated current council-house building programme of 'maybe more than 2,000' houses ('Built for speed: interview with John Healey', Society Guardian, 23 September 2009) is welcome, but too limited vis-à-vis the scale of current housing needs. The obvious danger is that without adequate underpinning public resources, a policy of localist particularism would simply replicate the kinds of tensions that Whitehead (2004) has highlighted in 
p. 150. Comments on 'New contexts, new challenges: revisiting equal opportunities, particularism, and ethnic relations' by Malcolm Harrison

the Walsall case. If that were so, we would be back in a position in which all that happens is that people living in deprived areas were promised that they will be 'empowered' (yet again), but in which the resources either do not follow this supposed empowerment, or if they do they only do so with centralist strings attached as in the case of housing stock transfers (Watt, 2008, 2009b, 2009c). If in practice localist particularism means devolving inadequate resources down to deprived small-scale areas, this will only stoke the already dangerous fires of intra-neighbourhood social distinctions and inter-neighbourhood turf wars.

* Correspondence Address: Paul Watt, Department of Geography, Environment and Development Studies, Birkbeck, University of London, Malet Street, London WC1E 7HX. Email: p.watt@bbk.ac.uk.

\section{References}

Cruddas, J. (2006) Housing policy failures and the rise of extremism, in: Defend Council Housing (ed.) The Case for Council Housing in 21 $1^{\text {st }}$ Century Britain. London Defend Council Housing, pp. 18-19.

DeFilippis, J. (2007) Erasing the community in order to save it? Reconstructing community and property in community development, in: $\mathrm{H}$. Beider (ed.) Neighbourhood Renewal and Housing Markets. Oxford: Blackwell, pp. 271-289.

Fuller, C. and Geddes, M. (2008) Urban governance under neoliberalism: New Labour and the restructuring of state-space. Antipode, 40, 2, 252-282.

Garner, S. (2009) Home truths: the white working class and the racialization of housing, in: K.P. Sveinsson (ed.), Who Cares about the White Working Class? London: The Runnymede Trust: pp. 45-50.

Harrison, M. (2009 forthcoming) New contexts, new challenges: revisiting equal opportunities, particularism and ethnic relations. People, Place and Policy Online.

Johnston, C. and Mooney, G. (2007) 'Problem' people, 'problem' places? New Labour and council estates, in: R. Atkinson and G. Helms (eds.), Securing an Urban Renaissance. Bristol: Policy Press:, pp. 125-139.

Watt, P. (2006) Respectability, roughness and 'race': neighbourhood place images and the making of working-class social distinctions in London. International Journal of Urban \& Regional Research, 30, 4, 776-797.

Watt, P. (2008) 'Underclass' and 'ordinary people' discourses: representing/representing council tenants in a housing campaign. Critical Discourse Studies, 5,4, 345-357.

Watt, P. (2009a forthcoming) Living in an oasis: middle-class disaffiliation and selective belonging in an English suburb. Environment \& Planning A, 41.

Watt, P. (2009b) Housing stock transfers, regeneration and state-led gentrification in London. Urban Policy \& Research, 27, 3, 229-242.

Watt, P. (2009c) Social housing and regeneration in London, in: R. Imrie, L. Lees \& M. Raco (eds.) Regenerating London. London: Routledge, pp. 212-233.

Whitehead, M. (2004) The urban neighbourhood and the moral geographies of British urban policy', in: C. Johnstone and M. Whitehead, M. (eds.) New Horizons in British Urban Policy. Ashgate: Aldershot, pp. 59-73. 
p. 151. Comments on 'New contexts, new challenges: revisiting equal opportunities, particularism, and ethnic relations' by Malcolm Harrison

\title{
Comment on 'New contexts: new challenges' by Malcolm Harrison
}

\author{
Ludi Simpson* \\ Cathie Marsh Centre for Census and Survey Research, University of \\ Manchester
}

In such a wide-ranging review it is not surprising to find a lot to agree with and some things to take issue with. I will confess to passing over some short-hand jargon with which I am unfamiliar, and concentrate on what I feel are points well made, some establishing truths and some raising less convincing ideas.

Malcolm is right to emphasise the common aspirations, conditions and expectations across ethnic and religious cultural boundaries. My own field of demography demonstrates how converging fertility rates and similar migration patterns of groups that statistics define as 'ethnic', lead to the growing ethnically diverse inner city neighbourhoods that policy leaders have misinterpreted as isolated ghettos (Finney and Simpson, 2009; Simpson and Finney, 2009).

$\mathrm{He}$ is right too that what Steve Vertovec (2007) has called the 'super-diversity' of minorities in the UK means that there is no longer a high correlation between minority ethnicity and disadvantage. There never was such a high correlation that stereotyping could be easily avoided, but it was high enough to paint a picture of wholesale disadvantage and marginalisation in policy that was real enough to be useful, but which is now no longer accurate.

Nonetheless it is not true that overt practices against settled minority groups would be hard to find today. A recent study showed the 17 out of 30 letting agencies and 25 out of 30 employment agencies were willing to satisfy clients' requests to allow access to White applicants only (BBC West, 2009). The viciously undemocratic aspirations of the far-right to represent a White majority are not so very far from mainstream politicians' ambitions to achieve and to stay in power. Malcolm rightly observes the failure of research so far to develop methods of monitoring and explaining how systematic inequalities and institutional practices develop over time.

Malcolm is right to name issues, such as the illegally bad working conditions experienced by many new immigrants, which are usually much more simple than the difficult debates over culture and immigration policy that undeservedly get more political attention. One can similarly point to anti-social behaviour as more relevant to community cohesion than friendship groups or residential composition.

Malcolm finishes by recommending local social housing groups for the income-poor as protective insulation from market and policy changes. Fair enough, although governments' promotion of local responsibility has tended to distract from the responsibilities of wider policy and market players (Amin, 2005).

Is Malcolm's final perceptive observation - that local collective responsibility such as through social housing organisations may diminish the ability of equal opportunity policy to protect individual rights of newcomers and other outsiders - a major issue or 
p. 152. Comments on 'New contexts, new challenges: revisiting equal opportunities, particularism, and ethnic relations' by Malcolm Harrison

a minor irony? That is for a question that the social housing organisations can be encouraged to discuss themselves.

* Correspondence Address: ludi.simpson@manchester.ac.uk

\section{References}

Amin, A. (2005) Local community on trial. Economy \& Society, 34, 612-633.

BBC West (2009) Racial discrimination, video and transcript. http://www.bbc.co.uk/insideout/content/articles/2009/01/09/west_discriminati on_s15_w1_feature.shtml

Finney, N. and Simpson, L. (2009) 'Sleepwalking to segregation'? Challenging myths about race and migration. Bristol: Policy Press.

Simpson, L. and Finney, N. (2009) Spatial patterns of internal migration: evidence for ethnic groups in Britain. Population, Space and Place, 15, 37-56.

Vertovec, S. (2007) Super-diversity and its implications, Ethnic and Racial Studies 29(6): 1024-54 
p. 153. Comments on 'New contexts, new challenges: revisiting equal opportunities, particularism, and ethnic relations' by Malcolm Harrison

\title{
Response to Malcolm Harrison 'New contexts, new challenges: revisiting equal opportunities, particularism, and ethnic relations'
}

\author{
Harris Beider* \\ Institute of Community Cohesion, Coventry University
}

I welcome Malcolm Harrison's overview. There is a need for discussion and debate in the area of public policy and equalities which seem strangely sterile and fixed in the past. The assumptions on equalities and legislation indeed need to be reviewed. In this response we will assess Harrison's discussion of economic liberalism and social regulation and the notion of particularism before putting forward ideas which may contribute to a new policy and research agenda.

The impact of economic liberalism and social regulation provides a basis for reflection. Of course the trend for both these apparently contradictory processes started long before the election of New Labour in 1997. However they seem to embody public management of the period since. The semblance of decentralisation alongside tight central control marks interventions on regeneration policies (New Deal for Communities) and equalities (new equality governance and the establishment of the Equality and Human Rights Commission).

At one level new public management has focused on management processes which seemingly seem to embed disadvantage. Policies based solely on representative outputs will inevitably lead to a 'tick box' mentality. Minority organisations and individuals had long had to fight implicit and explicit accusations of favouritism after successfully securing employment or resources. In these circumstances, leadership should have connected interventions to address disadvantage. There remains a need to emphasise the diversity dividend on personal and organisational development. Instead, excluded individuals and organisations feel disconnected from the politics of race. In short, policies apply to the minority rather than the majority.

Harrison seeks to develop this perspective in challenging particularism. Our perspective suggests that it would erroneous to ignore the specific and embedded disadvantage of some groups. This may be illustrated by two examples. First, Bangladeshi communities still face acute housing disadvantage many decades after migration and the passing of housing strategies designed to meet minority housing needs. Second, the position of refugee communities in the housing market demonstrates some of the problems with a policy which does not fully acknowledge the importance of race. Despite acute problems in accessing good quality housing, there appears very little likelihood that the new Homes and Community Agency will fund a new generation of refugee based housing associations in the same way that its predecessor, the Housing Corporation, developed specific Black and minority ethnic housing policies from 1986 which led to the creation of 66 minority led housing organisations. Disadvantage, exclusion and racism are still very salient to many people in the UK. Race should continue to be an important factor in shaping investment decisions. 
p. 154. Comments on 'New contexts, new challenges: revisiting equal opportunities, particularism, and ethnic relations' by Malcolm Harrison

In conclusion the real challenge is to conduct research that sharpens the issues and takes forward the debate. First, we need to reconfigure community cohesion. This means emphasising social justice and equality of opportunity as much as shared norms and values. Second, political leaders need to stress the value of diversity in the UK. This can be couched in terms of moving on from old Britain (looking to the past, such as World War Two and England winning the world cup in 1966 'and all that') and embracing a new Britain (creative industries, new technology and diversity). Third, we need to encourage modernity in thinking. Class remains important but let's not ignore race.

* Correspondence Address: Harris Beider, Institute of Community Cohesion, Futures Institute, 10 Innovation Village Coventry University, Technology Park, Cheetah Way Coventry, CV1 2TL. Email: aa4457@coventry.ac.uk. 
p. 155. Comments on 'New contexts, new challenges: revisiting equal opportunities, particularism, and ethnic relations' by Malcolm Harrison

\title{
Equal Opportunities in the UK as seen by a researcher from Turkey
}

\author{
A. Sule Özüekren* \\ Faculty of Architecture, Istanbul Technical University
}

\begin{abstract}
After reading the article of Malcolm Harrison I found some resonances with a paper of mine, especially on the boundaries and the difficulties of implementing a diversity agenda in order to reach a multi-cultural society. This encouraged me to write a response to expand the debate in this issue.
\end{abstract}

As a researcher from Turkey, I have never understood why people are classified according to their skin colour or ethnic background. Of course I am aware of the explanation stating its usefulness in measuring the equality, inequality or discrimination in a country. However, I have never seen scientific evidence for a difference among human beings according to their skin colour. Of course, the response to this observation is to point out that people observe the world through a racialised lens, projecting differences onto others (individuals/groups/societies) who look different from themselves and that this notion of race suffuses the social structure we inhabit. However, in Turkey the effect of race of everyday life has tended to be less obvious.

During the Ottoman era many ethnic groups lived side by side, maintaining their own culture while respecting other cultures. This situation continued until the weakening of the empire and the rise of rebel groups demanding independence. However, in the modern Turkey, the old tradition has continued and people have never questioned the ethnical background of their neighbours. This situation is in sharp contrast to the situation in the UK and can be explained by the fact that individuals cannot readily trace their family tree and therefore ethnic heritage in Turkey, a country that acts as a bridge between Asia and Europe and has expanded onto three continents during its history. It is hardly surprising that it is hard to find anyone claiming a 'pure' background. This is at least true for the Moslems of Turkey since, unlike Churches, there are no population registers at Mosques. Therefore, 'difference' has for many years meant little other than different cuisine, a different folk dance or a different song. Thus 'difference' has been something to learn and to share.

From a Turkish perspective, it is therefore very interesting to read Malcolm's observations about the complications of the ethnic/'racial' classification system in the UK in a period of changing circumstances. However, this contribution is disappointingly late, not for the UK, but for Turkey. While discussion in the UK is finally beginning to engage with the problematic aspects of classifying on the basis of ethnicity or race, in Turkey we are moving in the opposite direction. The diversity agenda is being imported from abroad. The role of liberal movements on this significant shift in Turkey is clear enough because, while ethnicity/religion/'race' gain importance in both academic and public discourses, socio-economic position of individuals, the weakening of trade unions or wage levels inadequate to meet even the basic needs are being left behind. Therefore, the changing agenda towards strengthening ethnic/religious/racial identities in the society obscures the position of the individuals in the labour market in 
p. 156. Comments on 'New contexts, new challenges: revisiting equal opportunities, particularism, and ethnic relations' by Malcolm Harrison

Turkey. This is not to say that we should not pay attention to individual rights. In our case, respecting the sustainability of the mother tongue - for example allowing citizens with Kurdish background to maintain their mother tongue if they want to do so - is an important democratic development. But the problem, as Malcolm writes, is the difficulties in expanding specific services according to different needs. The same holds true for the broad category of 'Muslim' because Islam has been interpreted differently in different countries - indeed differently within a single country like Turkey. Therefore, classification of 'Muslims' as a monolithic category would similarly pose difficulties in meeting the different needs of different Moslem groups.

Malcolm draws our attention to all types of 'the others' in the society but pays less attention to the divisive role of multicultural policies. I argue that more important than the difficulties in implementing a diversity agenda is its role in cementing different identities like the 'blackness', 'the whiteness' or 'the Muslim identity' and in constructing boundaries between groups, disadvantaging 'the internal others' within the others, such as females, non-religious or secular individuals, and indeed the children who are shaped by their parents and society as a whole.

* Correspondence Address: A.Sule Özüekren, Faculty of Architecture, Istanbul Technical University, Taskisla, 34 437, Istanbul, Turkey. E-mail: ozuekren@itu.edu.tr. 